\title{
Biological Warfare-The Real Pandora's Box: Learning From the Past
}

\author{
Alexandru Herciu \\ “Carol 1st” National Defense University, Bucharest, Romania
}

\begin{abstract}
It is necessary to assess the risks generated by various micro-organisms that can be used as biological weapons and to understand the process of their development and the use of biological agents over time. Biological agents used for military purposes may be more powerful than conventional weapons and chemical weapons. Over the past century, advances in biotechnology and biochemistry have simplified the development and production of such weapons, and genetic engineering probably holds the most dangerous potential for making biological weapons. Ease of production, broad availability of biological agents and technical knowledge has led to the proliferation of biological weapons and a growing desire among developing countries to hold them.
\end{abstract}

Keywords: biologic warfare, biological agents, Biological Weapons Convention, bioterrorism

\section{Introduction}

The biological weapon is the means of mass destruction, sometimes difficult to control, which through the harmful effect of pathogens (viruses, bacteria, rickettsia, and microbial toxins) can cause large losses among troops, populations, and animals, as well as the destruction (contamination) of crops. Also called the nuclear bomb of the poor or the dirty bomb, it is an invisible weapon. It can be transported without being detected, even across borders, in sufficient quantities for a major attack.

Micro-organisms can be released without noise and without causing immediate effects. The disease cannot be determined until the symptoms of the infection and the biological agent are identified. If the biological agent can be easily spread from one person to another, the number of victims can easily reach tens of thousands of cases.

Since September 11, 2001, the danger of large-scale terrorist attacks against the population of any part of the world no longer seems to be an unimaginable scenario. Biological terrorism is no longer in the field of science fiction. There are opinions that the possibilities of a terrorist attack with biological weapons are very low, but there may be disastrous consequences if no immediate action is taken.

Biological attacks represent the evolution of the etiological agents of infectious diseases (natural or genetically engineered) spread to the environment with two purposes: to produce a catastrophic effect on the civilian population (a large number of serious illnesses and deaths) which sometimes outweighs the responsiveness of medical units and to induce the fear and terror within the population, what is known as "bioterrorism".

Alexandru HERCIU, Lieutenant Colonel, Ph.D., Associate Professor, Land Forces Department, Command and Staff College, "Carol 1st" National Defense University, Bucharest, Romania. 
It is certain that most of the world's states hold the economic and military potential to acquire or manufacture biological weapons, and this fact has been proven many times throughout history.

\section{Historical References}

The impact of infectious diseases on humans has been used from military perspective since $600 \mathrm{BC}$. The use of human and animal dead bodies to spread contagious diseases during battles, and especially during siege of cities, has proven to be a very effective and devastating effect on enemy forces. The poisoning of fountains and other sources of water has been a military strategy of biological warfare for hundreds of years, continuing to be used even during the world wars of the 20th century.

Military leaders of the Middle Age observed that the victims of infectious diseases can turn into biological weapons that could be successfully used against the enemy. In 1346, during the siege of Caffa, a maritime port on the Crimean Peninsula controlled by the Genoese (now Feodosia, Ukraine), the Tartars catapulted the victims of the plague over the walls of the city, triggering an epidemic of plague in the city. Thus, the outbreak of plague forced the withdrawal of Genoese forces and the conquest of the city by the Tartars (Wheelis, 2002).

The Caffa Incident was described in 1348 by Gabriel de Mussis, a notary from Genoa, who came up with an important hypothesis in the fact that the plague was passed on to Caffa citizens by throwing diseased bodies into the besieged town, and the Italians fleeing from Caffa brought the plague into the Mediterranean ports (Derbes, 1966). More specifically, the ships that carried the plague-infected refugees sailed to Constantinople, Genoa, Venice, and other Mediterranean ports and were believed to have greatly contributed to the outbreak of the greatest biological disaster in human history, the pestilence of the 14th century plague that killed over 25 million people only in Europe.

The plague pandemic, also known as "black death", passed through Europe, the East Asia, and North Africa in the 14th century and was the most devastating public health disaster in history. The initial origin of the plague remains uncertain, as several countries in the Far East, including China, Mongolia, and India, have been suggested.

However, considering the complex environmental causes and epidemiology of the plague, the assumption that a single biological attack was the cause of the pestilence pandemic in Europe in the 14th century may have been exaggerated, but the Caffa biological attack despite its historical importance, reminds us of the terrible consequences of diseases when used as weapons.

It is also argued that the Russian troops have used a similar procedure against the Swedes in 1710. It is also known the struggle of the Romanian Countries for liberation from the foreign occupation in the Middle Ages when, during the wars, different means were used for defense like poisoning of fountains with "banewort broth".

In the 15th century, Pizzaro offered smallpox infected clothes to South American natives, and during the Anglo-French war in North America in the 16th century, the English distributed infected blankets to the American tribes that helped the French, led to the withdrawal of indigenous support for them (Christopher, Cieslak, \&Pavlin, 1997).

The biological weapon had a fast development at the end of the 19th century and throughout the 20th century, given by the new findings in biochemistry. Thus, at the start of World War I, anthrax was used on animals but it proved to be inefficient. Subsequently, during the same confrontation, there were epidemics of almost all kinds: measles, influenza, typhoid fever, and various pneumonia types that produced a significant 
loss of human lives (A. G. Robertson \& L. J. Robertson, 1995).

During the Japanese occupation in China between 1934 and 1945, the Japanese army has built up a specialized biological agent's center in Manchuria, in order to test their impact on human. For more than 10 years, thousands of Chinese, Korean, Russian, and American people have been massacred in these factories of death (Kwantung Unit 731 and Changchun Unit 100) during experiments to determine the effects of military using of plague, cholera, anthrax, typhoid fever, and dysentery (Harris, 1994).

In September 1978, the Bulgarian secret police used the ricin toxin in order to murder the dissident Georgi Markov in London.

In 1979, anthrax accidentally released in Sverdlovsk, Russia, killed 66 people; and in 1992, President Boris Yeltsin admitted that the tragedy was due to an accident in a biological weapons laboratory.

In 1984, in Oregon, the religious cult of Rajneeshe contaminated food from eight restaurants, with salmonella typhimurium in order to influence the local elections, 751 people being contaminated.

In 1995, the Japanese Aum Shinrikyo sect used three bottles of botulinum toxin and anthrax bottles placed in Tokyo subway stations (failed attack). In 1998, the same sect has spread anthrax spores from the eighth floor of a Tokyo building. The members of this group later acknowledged that they tried to obtain samples of the Ebola virus from Zaire in 1992 (US Army Medical Research Institute for Infectious Diseases, 2001).

In 1995, two members of a Minnesota militia group were convicted of possession of ricin toxin, which they had produced themselves for use in retaliation against local government officials.

After the events of September 11, 2001, letters containing anthrax spores were sent to National Broadcasting Company (NBC) and New York Post. Other letters have targeted Washington, government offices, and post offices. The result is five dead.

In December 2002, six terrorist suspects were arrested in Manchester, England, because their apartment was serving as a "ricin laboratory". Later, on January 5, 2003, British police raided two residences around London and found traces of ricin toxin, which led to an investigation of a possible Chechen separatist plan to attack the Russian embassy with the toxin; several arrests were made.

On February 3, 2004, three US Senate office buildings were closed after the ricin toxin was found in a mailroom.

In recent years, due to major social changes in the world, as well as the spread of organized crime networks, access to these types of weapons by groups that promote, fund or support various forms of terrorism is much easier than we might think.

\section{The Main Biological Threats Against Humanity}

Biological warfare is not and cannot be a reaction to despair because it requires a serious material basis, well-equipped laboratories, high-class specialists, very high costs, and thorough training.

An extremely important aspect to be considered about the fight against the biological weapon is that there is no reliable means of detecting biological agents released into the atmosphere in large areas, such as the cities. Biological attacks are recognized only after the affected population has started to get ill, sometimes depending on the incubation period, even weeks, or months after the attack.

Smallpox and hemorrhagic fever virus, anthrax bacillus, and botulinum toxin are weapons selected by states that have a program of biological weapons. These weapons are also in the spotlight of terrorist groups.

Thus, a biological agent can be considered to be any micro-organism or toxin characterized by the ability 
to cause illness or death of a living organism, the most dangerous of which is considered to be:

(a) Biological agents that can seriously affect public health, with high potential for large-scale dissemination:

1. Smallpox. It is transmitted from person to person, through direct contact or via a contaminated object, but not by water or air. If used as a biological weapon, smallpox is a serious danger to the population. It is a very contagious disease. In the absence of specific treatment, mortality reaches $30 \%$ of unvaccinated persons. Symptoms occur 12 to 14 days after contamination: high fever, headache, and lumbar pain. Isolation of patients and vaccination allow the epidemic to stop. The treatment is limited to the administration of specific antibiotics to bacterial infections. Early vaccination against smallpox is not warranted because the vaccine may be dangerous. This disease is considered to be eradicated since 1979, and since 1984 vaccination is no longer mandatory. ${ }^{1}$

2. Anthrax. It is an infectious disease caused by the spores of a bacterium, Bacillus anthracis that can be transmitted by the skin or respiratory system. For centuries, animals and humans have been the victims of this disease. Research on this micro-organism as well as its use as a biological weapon dates back to 1980. Currently, 17 countries are suspected of having such an arsenal. In the event of a terrorist attack, airborne transmission is the most dangerous. Symptoms occur in seven days, manifested by irritations similar to those caused by insect bites. This disease became serious in the absence of treatment, but known bacilli are sensitive to antibiotics. In the absence of appropriate treatment, mortality is $20 \%$ due to septicemia. Respiratory patterns are generally deadly, and for intestinal infections, the mortality is $25 \%$ to $60 \%$ (The Center for Biosecurity, 2011).

3. Plague. It is an infectious-contagious disease produced by the bacterium Yersinia pestis, and still exists in certain parts of the world. It is transmitted most frequently by wild rodents through fleas. Due to the fact that the germs responsible for the transmission of the disease are sensitive to antibiotics, it can be easily treated if done in time. Every year, the World Health Organization reports between 2000 and 4000 cases of plague worldwide. It is manifested by high, oscillating fever, often accompanied by delirium and hallucinations, as well as intense digestive disturbances. Its characteristic sign is the presence of a "bulb wound", a very bulky ganglion. The mortality rate is between $50 \%$ and $90 \%$ for untreated cases and $15 \%$ for treated cases.

4. Tularemia. It is a viral hemorrhagic fever caused by Francisella tularensis virus with a mortality of between $25 \%$ and $100 \%$ of cases.

5. Botulism. It is a very dangerous condition in manifestation, caused by Clostridium botulinum (botulinum toxins). It can contaminate drinking water, can be introduced into food, or disperse into the atmosphere. Since botulinum toxin is sensitive to chlorine from the water, large-scale contamination is unlikely to occur through the drinking water network. Ingestion, inhalation or eye contact, or a skin lesion with a small amount is sufficient to cause serious poisoning and deadly neurological disorders. Classical symptoms are: visual disturbances, difficulty in swallowing, and extreme fatigue. If the symptoms are not rapidly diagnosed, limb and respiratory paralysis is installed. In case of ingestion, the first symptoms occur between 15 and 36 hours. It can be treated with an antitoxin that will prevent the most serious manifestations: respiratory failure and paralysis. Fifty years ago, $50 \%$ of cases were fatal but at present only $8 \%$ of cases pose risks.

\footnotetext{
1 SA Health, Smallpox-including symptoms, treatment and prevention, available online at: http://www.sahealth.sa.gov.au/ (accessed on October 27, 2018).
} 
6. Viral hemorrhagic fever (Lassa fever, Ebola fever). They are extremely contagious, in most cases fatal and untreatable. Rodents and insects are the main "reservoirs" of viruses. Humans may become infected by contact with virus-carrying animals or urine, saliva, excrement, blood, or secretions of a sick person (E bola). The main symptoms are: very high fever, fatigue, dizziness, spasms and muscle aches, and exhaustion. In the case of Ebola fever, the patients are victims of multiple hemorrhages in the digestive system, lungs, and eyes. As a biological weapon, haemorrhagic fevers are less effective because the contaminated subject dies so quickly that it does not have time to spread the disease. Besides, these viruses are also very difficult to handle. There is no treatment or prophylaxis for haemorrhagic fevers. For Ebola, mortality is between $50 \%$ and $90 \%$ of cases.

(b) Agents which are relatively easy to disseminate and have low mortality rates:

1. Brucellosis (Brucella spp.) - infectious disease caused by the Brucella-type bacterium that is transmitted between animals. Humans can be infected after contact with animals.

2. Viral encephalitis - alpha viruses induced disease, such as horseradish encephalitis, but most commonly those responsible for mumps, rubella, measles, influenza, and mononucleosis (Epstein-Barr virus). These viruses can cause serious illnesses and in some situations they can infect the brain and cause encephalitis.

3. Cholera-acute infectious disease caused by cholera virus (Vibrio cholerae), which causes a serious alteration of the general condition and the progression to mortality in 50 to $80 \%$ of the untreated cases.

4. Staphylococci-infectious diseases caused by staphylococci (Gram positive bacteria) present in the air, in water, and on all surfaces; the man hosts them in the nostrils, intestine, sweat glands, and on the skin.

5. Ricin-toxin produced by ricinus communis plant. Under certain conditions-injected, swallowed, or inhaled-it is very dangerous; there is no antidote. If it reaches the airways, death occurs within 36-48 hours.

(c) Pathogens that can be performed in the laboratory and which have a high potential for causing morbidity or mortality (examples: nipah virus and drug-resistant tuberculosis).

\section{Non-proliferation of Biological Weapons and Awareness of the Bioterrorism Threat}

Proliferation of weapons of mass destruction (nuclear, biological, and chemical) is a phenomenon that can generate serious threats and dangers to international security. The casuistry in the matter confirms that groups that possess or are trying to acquire such weapons are constantly growing. They can escape control, despite the efforts of the international community to prevent their use.

The proliferation of biological and chemical weapons is to a large extent recognized as a growing international security issue, both in the event of an inter-state conflict and as a potential dimension of terrorism.

The 1925 Geneva Protocol prohibits the use of chemical and biological weapons. The states parties to the Biological and Toxin Weapons Convention (BTWC) have agreed not to develop, produce, store, or acquire biological agents and related equipment for hostile purposes.

Subsequently, the "Convention on the Prohibition of the Development, Production and Stockpiling of Bacteriological (Biological) and Toxin Weapons and on their Destruction" was drafted in 1972, known as Biological Weapons Convention (BWC) (United Nations Office for Disarmament Affairs [UNODA], 1972). This treaty prohibits the development, production, and storage of pathogen agents or toxins in "quantities that have no justification for prophylactic, protective, or other peaceful purposes". In accordance with BWC, it is also forbidden to develop delivery systems and the transfer of biological technology or biological expertise to other countries. In addition, the signatories to the BWC requested to destroy stockpiles, delivery systems, and 
production equipment within nine months of ratification of the treaty. This agreement was signed by 103 nations and the treaty was ratified in April 1972. The BWC came into force in March 1975. Signatories who have not yet ratified the BWC are obliged to refrain from activities that would defeat the purpose of the treaty until they communicates specifically to the UN their intention not to ratify the treaty. The BWC review meetings took place in 1981, 1986, 1991, and 1996. The BWC signatories are required to present UN the following information annually: facilities in which biological research activities are carried out, scientific conferences taking place at specified facilities, exchange of scientists or information, and outbreaks of diseases (US Arms Control and Disarmament Agency, 1996).

In 1994, a special conference set up an ad hoc group of states participating in the Convention to examine possible verification measures and proposals to strengthen the Convention. The 4th Review Conference, which took place in 1996, agreed to conclude a Protocol as early as possible before the start of the 5th Review Conference in 2001. During its meeting on 24 May 2000, in Florence, North Atlantic Treaty Organization (NATO) countries reaffirmed their support for this goal.

Because of international events, there have been a growing number of recent developments in biological weapons, terrorist biological attacks, in a word, bioterrorism. The interest of these groups for chemical and biological weapons is worrying even more. Heads of terrorist organizations have openly expressed their intention to take possession of and use weapons of mass destruction. This desire certainly raises serious concern and poses a threat to all nations.

Some authors even think that a new era, a post-nuclear threat, in which the biological threat takes the place of the nuclear threat, has begun. At present, the "Trojan horse" of international terrorism is bioterrorism, and that is because the main target of the bioterrorist attack is the civilian population.

Bioterrorism, a component of terrorism, is the deliberate use or threat of using biological (etiological) agents of infectious diseases (viruses, bacteria, parasites, and fungus), their toxins, plant toxins, bio-regulators, and materials contaminated with them, in order to induce the death of humans, animals, or plants and spread anxiety, fear, and terror; and to intimidate a person, a specific group of people, or a country's population for religious, political, ideological purposes, financial, or personal interests. Bioterrorism can also be directed against food and feed reserves, food preparation and storage facilities, and water supplies.

The interest of terrorists in chemical and biological weapons has increased especially since the Tokyo subway attack, and there is evidence that some terrorist organizations and groups have a particular interest in chemical and biological means.

Bioterrorist attacks are considered by most people to be mysterious, non-discriminatory, uncontrollable and unpredictable, and difficult to dissociate from a natural epidemic, all of these characteristics generating a state of collective anxiety.

The means by which bioterrorist actions are carried out, are divided into three categories: known, suspected (possible), and unknown. For those currently known (own laboratories, different enterprises of the chemical and pharmaceutical industry, drug and toxin manufacturing facilities, transport and dispersal facilities at the target, etc.) and for those likely to be used, measures can be envisaged appropriate countermeasures and protection.

More difficult to counteract are those that are still unpredictable. These means are based in particular on modern biotechnologies and, in particular, on genetic engineering research. New discoveries on genomics and genetic changes are already being applied in agriculture and animal culture, and the current outcomes (creation 
of mutants, bacteria, viruses, etc.) start to be worrying. A biological attack will only be detected when the first symptoms or even the first victims occur. This delayed effect also gives bioterrorism a great deal of efficacy.

Regarding the purchase of biological agents, although procurement may be legally motivated, it can still cover criminal activities. For a terrorist, procuring a pathogen or a source of toxins to produce and disseminate a biological weapon is a challenge. Thus, it is possible to purchase biological agents even with the support of a government (national programs of biological weapons), by diversion of substances on the travel itinerary by the theft from specialized institutions in this field (universities, industrial societies, or microbiology laboratories) by purchasing from the black market or even extracting from natural sources.

At the same time with the acquisition and production of biological agents, there are several methods that allow the isolation, cultivation, and purification of biological materials for later use as weapons, processes that do not necessarily require advanced professional training or the need for specialized equipment. Both libraries and the Internet provide a wealth of detailed information on the preparation of clandestine biological agents.

Some countries, like France, took the risks of bioterrorism seriously. The BIOTOX Plan, created after September 11, 2001, provides for the reconstitution of vaccine stocks against biological agents, 24-hour intervention facilities for specialized laboratories, and the provision of special materials to hospitals to deal with chemical and biological risks (Marrs, Maynard, \& Sidell, 2007). Water chlorination has been increased to neutralize potential contamination of drinking water networks. A surveillance institute is tasked with detecting health emergencies as early as possible and collecting signals on anthrax, meningitis, etc. Great Britain, Ireland, and the US have practiced, especially at the subway, alert exercises to test the ability to react to a biological attack on the population.

In the United States, counter bioterrorism plans exist at the level of each state, drafted just before September 11, 2001. Other states reconstitute their vaccine stocks. Israel has a quantity that will allow it to vaccinate the entire population. In France, 60 million people can be vaccinated within 15 days if necessary. Germany has 100 million doses of smallpox vaccine ${ }^{2}$. However, all these precautionary measures involve huge costs. Risks are at the planetary level, for example, there are no borders in the way of smallpox or plague. The threat is global and therefore the retaliation must also be in the world.

The World Health Organization provides national and international assistance to cope with both consequences of the use of biological weapons and deliberately created "epidemics". For example, the severe acute respiratory syndrome (SARS) epidemic has contributed to speeding up the awareness of the biological risks and the impact of economic damage caused by a possible epidemic in a globalized economy.

Each state must undertake to protect its population at present and in the future against the consequences of terrorism, taking into account two legitimate objectives: the life and security of the population respecting human rights and fundamental freedoms. Effective population protection requires overcoming national interests and recognizing effective combat against the consequences of bioterrorism.

Optimistic scenarios confirm that there are no "perfect biological weapons". Infection vectors are currently sensitive to known antibiotics. Others, like botulinum toxin, are relatively fragile and non-toxic. Currently, the use of biological weapons could cause a certain number of deaths, but not scary epidemics. However, the pessimistic scenario remains, with the hypothesis of the bacterium resistant to all existing antibiotics through

2 World Health Organization (Fr.), Vaccination, vaccins et produits biologiques, available online at: http://www.who.int/immunization/global_vaccine_action_plan/fr (accessed on October 27, 2018). 
genetic manipulation, a science-fiction scenario.

\section{Conclusion}

Considering the above-mentioned aspects of biological warfare agents, we need to learn from the experiences of the past in order not to face similar situations at present or in the future.

Some experts believe that manufacturing of biological weapons is available for many "amateurs". Anyone with advanced knowledge in microbiology could manufacture their own nucleotide synthesizers-devices that serve to set up complex genetic structures. This technology is only at its beginnings, but biologists might someday use it to cause subtle mutations of already known microbes. If these diseases would resist to existing vaccines, their potential to kill would have no limits.

Thus, from the point of view, for a coherent bioterrorist riposte, it is necessary to combine several protective measures, starting with the prevention of the terrorist attacks. For this purpose, the international intelligence structures have developed programs to make the activities of potentially dangerous groups known and supervised strictly. In this area, it is absolutely necessary to step up exchanges of information between structures, agencies, and cooperation between states, whose input is vital to the creation of an effective international system to counter any attempts to use biological weapons. Also, we consider that greater attention should be paid to monitoring the traffic of biological agents, even though most of them are dual-use products, demanding export controls, or any exchange of raw materials, in order to reduce the possibilities for terrorist groups to obtain them.

Another important aspect we consider as the education of the civilian population regarding the way of protection and action in case of a mass destruction weapon attack. Another issue that we consider to be important is the education of the civilian population on how to protect and act in the event of a mass destruction weapon attack. Appropriate protection measures, psychological aspects, or support to institutions with incident management responsibilities with a focus on victims care, should be considered here. If military units are equipped, trained, and trained to carry out operations in biological environments, civilian population is exposed to such a danger without the possibility of an effective response.

In this respect, we appreciate the importance of investing in specialized technology for the detection of biological warfare agents. At national level, institutions with responsibilities are interested in acquiring these devices. The Romanian Army has specialized structures for the detection of biological warfare agents and laboratories for the analysis of suspicious samples to be biologically contaminated, some of which are being homologated at this time.

At the same time, in order to counteract the terrorist threat, at the strategic level, we believe that the fight for non-proliferation must continue. All democratic states need to strengthen their legislation in the field, including the production, development, and illegal possession of biological agents, on the list of major crimes against national security. "Convention on the Prohibition of the Development, Production and Stockpiling of Bacteriological (Biological) and Toxic Weapons and their Destruction" of 1972 provides that States Parties shall take the necessary measures to ensure that prohibitive provisions of the Treaty become binding on all citizens.

In conclusion, the understanding of the real nature of the biological weapons threat, the efforts to stop their proliferation through strict control of exports and imports of dual-use agents and equipment, harmonization of legislation, exchanges of information on the purchase of biological agents, and a strong reaction, nationally and 
internationally, against countries that do not comply with the 1972 Convention, could discourage those who intend to use such weapons of mass destruction.

\section{References}

Christopher, G. W., Cieslak, T. J., \& Pavlin, J. A. (1997). Biological warfare: A historical perspective. Journal of the American Medical Association. Retrieved October 26, 2018, from http://books.google.ro/books

Derbes, V. J. (1966). De Mussis and the great plague of 1348. Journal of the American Medical Association. Retrieved October 26, 2018, from http://jamanetwork.com/journals/jama/article-abstract/658907

Harris, S. H. (1994). Factories of death: Japanese biological warfare, 1932-1945, and the American cover-up. Retrieved October 26, 2018, from books.google.ro/books

Marrs, T. C., Maynard, R. L., \& Sidell, F. R. (2007). Chemical warfare agents: Toxicology and treatment. Retrieved October 28, 2018, from https://onlinelibrary.wiley.com/doi/book/10.1002/9780470060032

Robertson, A. G., \& Robertson, L. J. (1995). From asps to allegations: Biological warfare in history. Military Medicine, 160, 369-373. Retrieved October 26, 2018, from books.google.ro/books

The Center for Biosecurity. (2011). Bacillus anthracis (Anthrax). Retrieved October 27, 2018, from http://www.upmc-biosecurity.org/website/our_work/biological-threats-and-epidemics/fact_sheets/anthrax.html

United Nations Office for Disarmament Affairs (UNODA). (1972). Convention on the Prohibition of the Development, Production and Stockpiling of Bacteriological (Biological) and Toxin Weapons and on their Destruction. Retrieved October 27, 2018, from http://www.un.org/disarmament/wmd/bio

US Arms Control and Disarmament Agency. (1996). Arms control and disarmament agreements: Texts and histories of the negotiations. Retrieved October 28, 2018, from http://babel.hathitrust.org/cgi/pt?id=pur1.32754066656608; view=1up;seq=3

US Army Medical Research Institute for Infectious Diseases. (2001). Medical management of biological casualties handbook (4th ed.). Retrieved October 26, 2018, from http://www.au.af.mil/au/awc/awcgate/med01bio/bluebooktitleand disclaimer.pdf

Wheelis, M. (2002). Biological warfare at the 1346 siege of Caffa. Emerging Infectious Disease, 8(9). Retrieved October 25, 2018, from http://wwwnc.cdc.gov/eid/article/8/9/01-0536 